\title{
Evaluation and Calculation of Dynamics in Environmental Impact Assessment
}

\author{
Björn Johansson*, Jon Andersson, Erik Lindskog, Jonatan Berglund, \\ and Anders Skoogh \\ Production Systems, Chalmers University of Technology, Gothenburg Sweden \\ \{bjorn.johansson, jon. andersson, erik, lindskog, \\ jonatan. berglund, anders.skoogh\} @chalmers.se
}

\begin{abstract}
In ten years customers will select products not only based on price and quality but also with strong regard to the product value environmental footprint, including for example the energy consumed. Customers expect transparency in the product realization process, where most products are labeled with their environmental footprint. Vigorous companies see this new product value as an opportunity to be more competitive. In order to effectively label the environmental impact of a product, it is pertinent for companies to request the environmental footprint of each component from their suppliers. Hence, companies along the product lifecycle require a tool, not only to facilitate the computing of the environmental footprint, but also help reduce/balance the environmental impact during the lifecycle of the product. This paper proposes to develop a procedure that companies will use to evaluate, improve and externally advertise their product's environmental footprint to customers.
\end{abstract}

Keywords: Discrete event simulation, sustainable production, product lifecycle, environmental analysis, sustainable manufacturing.

\section{Introduction}

Conscious efforts on reducing environmental impact are valuable for companies. Such companies contribute not only to a more sustainable future, but also obtain a competitive advantage towards customers. One example from food and service industry is an award winning restaurant in Sweden called MAX. They reported a reduction of their $\mathrm{CO}_{2}$-emmisions by 44\% [1] between 2007 and 2008 by evaluating and improving their product value chain. Moreover, market research shows that 13 times [2] more customers relate their brand to environmental friendly products compared to their main competitor. MAX's sustainability manager states that the latter figure is not the result of an increase in traditional marketing, but derives solely from communication of their products' environmental footprint. This paper describes a current research project called EcoProIT enabling manufacturing industry to evaluate, improve and advertise their environmental footprint through the developed procedure.

\footnotetext{
* Corresponding author.
} 
At present, Life Cycle Assessment (LCA) standardized by ISO 14040:2006 and 14044:2006 [3] is by far the most common analysis method for evaluation of environmental footprint. However, there are inherent problems associated with LCA, which reduce its preciseness and limit its value for companies. The main associated problems with traditional LCA analyses are [4]:

- Use lumped parameters and site-independent models.

- Static in nature and disregard the dynamic behavior of industrial and ecological systems.

- Focuses only on environmental considerations, not economic or social aspects.

Hence, it is important to complement LCA with other analysis tools, in order to effectively combine environmental and economic analysis. The EcoProIT project in particular proposes Discrete Event Simulation (DES) as a potent solution, thereby reaping the strengths of DES to perform dynamic and site-specific analyses on product flows along product value chains. Combining the advantages of DES with LCA compensates the above stated weaknesses of traditional LCA. Performing DES and LCA simultaneously in a product value chain offers the advantage to foresee the interaction between resources and helps identify opportunities to reduce waste. In other words, companies will be able to use the EcoProIT tool [5] with combined capabilities of DES and LCA, to label their products and to increase competitiveness. The tool enables continuous improvement of the product realization process with regard to both efficiency and environmental footprint.

\section{State of the Art}

\subsection{Combined Environmental and Production Systems Analysis}

To solve the inherent problems of LCA there are proposals on combining tools for environmental analyses (usually LCA) and tools for evaluation of industrial systems. For example, ecosystem models are combined with basic industrial models such as Activity Based Costing (ABC) [3] and in [6] environmental analyses are combined with the process mapping approach Value Stream Mapping (VSM). Regarding the dynamic aspects, LCA has been combined with Monte Carlo simulations [7] and initial studies have also been performed on integration of LCA and DES [8].

However, the bottom line is that researchers in the area agree on that this is still an immature research area with significant potential [6]. The potential for reducing environmental impact with means of production flow development is actually bigger than the potential of addressing individual manufacturing processes [9]. New research (NIST-Chalmers-Boeing-collaboration) show that more energy is saved by reducing the production lead-time of a product compared to reductions in energy consumption for the value-adding machining processes, which is due to the high energy consumptions during stand-by times of the machines. An additional factor regarded in this project proposal is the potential to benefit from synergy effects from analyzing production and logistic processes throughout the complete product value chain including recycling. This potential is previously evaluated by e.g. [10]. 


\subsection{Data Management and Model Credibility}

Data management is one of the biggest problems in LCA [3] [4] and this has also traditionally been a problem for production development tools such as DES. An indicator is that $31 \%$ of the time for DES is spent on input data management [11]. However, recent research proposes a higher level of automation and integration of data sources in the input data management process [13] [14] and the proposed project will contribute to the incorporation of environmental data in this process. One part in this work is the cooperation with the United States National Institute of Standards and Technology (NIST) on adding environmental parameters to the Core Manufacturing Simulation Data (CMSD) standardization effort [15].

Another important part for model and analysis credibility is to apply a structured and transparent work procedure. This point has recently been addressed in the DES area by efforts from the Fraunhofer Institute in Germany [16] and similar work has also been performed to support combined DES and LCA [5]. The proposed project will contribute to this work by extending these work procedures to regard the entire product value chain and assure correct standardized analyses and trust between involved parties enabling benchmarking between products and companies.

\section{Project Description}

The EcoProIT project brings together researchers on production and environmental system analysis with industrial partners throughout the complete lifecycle of a specific product used in forklift manufacturing. The product is analyzed in three separate settings, raw material extraction/recycling, sub component manufacturing,

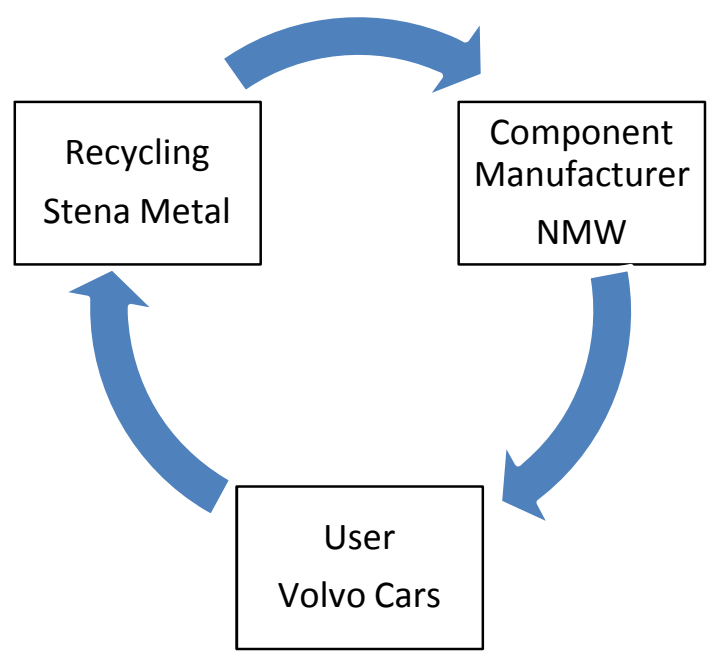

Fig. 1. For development and demonstration of the EcoProIT tool, the project will regard companies through the lifecycle of a product 
final product manufacturing/use, and then recycled back to the raw material state again. The total cycle will be closed when all three company specific case demonstrators are done, they will then be merged into the complete lifecycle calculation of environmental footprint.

There are three main scientific challenges addressed in the project:

- Efficient management of environmental data.

How can required data for production performance and environmental impact be jointly collected and processed in an efficient manner?

- Selecting system delimitations.

How are the system delimitations chosen to ensure objective measurements and, thus, enable comparison?

- Modeling methodology through an entire product lifecycle.

How are models built and communicated between companies involved in the product lifecycle, in order to assure company integrity as well as correct standardized and credible analyses?

\section{$4 \quad$ Level of Innovation}

Today, industry can evaluate and declare their products' environmental footprint only for marketing purposes. This is for example applied in several cases in food industry. However, due to limitations in the traditional LCA analysis it is problematic to detailed process analyses and specific results. These drawbacks make it impossible for a specific company to really improve their performance and compete on their environmental footprint.

The proposed tool enables not only declaration of environmental footprint but also continuous work with reduction of this new product value. Furthermore, the tool adds the factors time, location and economy to traditional LCA analyses. The bottom line is that companies in all lines of business can reduce environmental impact and improve economic profit simultaneously. The EcoProIT tool will be associated with competitiveness on the product values price and environmental footprint in Swedish manufacturing industry.

The significant value in definition of measurements for sustainability performance in manufacturing industry is one contribution. Moreover, the research on dynamic and site specific evaluation of environmental effects in production systems is a requested and not yet researched complement to the popular LCA analysis [3]. Several other actors are identified and collaboration is established with most of the twelve actors described by Herrmann et al. [17] in order to streamline work and reach interoperable and useful results for industrial applications. 


\section{Vision}

Product Lifecycle Management (PLM) systems are widely used in large manufacturing companies. They are used to support collaborated work throughout a products life cycle. To conduct the analysis explained in this paper, a structured work method and a helpful tool is needed. However, to support collaborative work between companies and other actors in a life cycle a larger data management system is needed. This project proposes to use PLM likewise software and database structure to enable sharing of results and information. All companies that are involved in a products lifecycle connect to the database structure and share up to date result and analyze. This enables up to date emission declaration for the products analyzed in the system. Figure 2 show how the close linked companies share all information and final result to the public server available for other companies to use in similar studies.

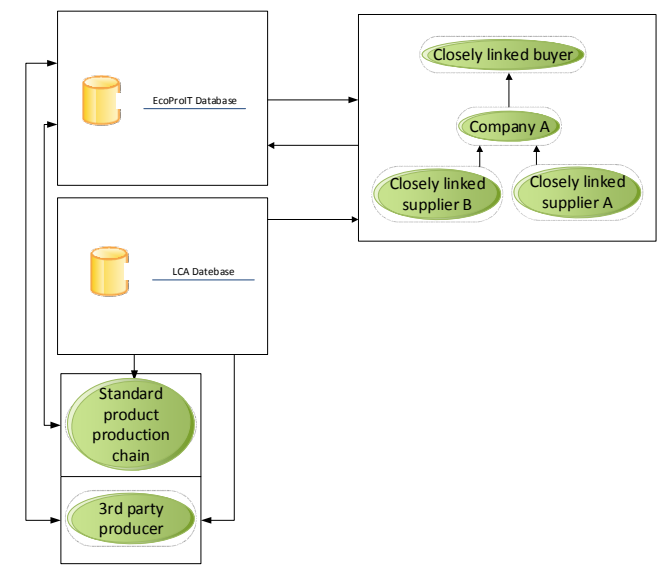

Fig. 2. Conceptual data repositories for lifecycle assessment data

\section{Present Status}

The project has reached halfway and two of three parts in figure 1 are completed. The first case study show several advantages with the proposed method compared to LCA concerning the level of details, scalability and dynamical emission values. Results from the study indicated that a large part of the total emission value was related to processes outside the studied company, which directs the need for applying the method to the entire life cycle. The first case study resulted in a proposed method for future work with focus towards the process of gathering environmental input data.

The second case study show how to build a structured output data format that supports validation and verification of the model. Practical experiences show that it is important to early identify the expected input data and information that is possible to retrieve. A DES model built for LCA calculations need other types of information from the real system, i.e. energy consumption and resource consumption for specific processes. Depending on available information the model can be alternately designed. 


\section{$7 \quad$ Future Research}

There are additional efforts ongoing within the field of DES-LCA combination. Examples stated in [18-29] are many different approaches on how to describe instantiated DES-LCA case studies. The majority of these researchers are now working together to find a common solution on how to utilize DES and LCA in a methodological manner to calculate benefits of the combination.

Acknowledgements. The authors would like to acknowledge support from ProViking through the EcoProIT project and VINNOVA (Swedish Agency for Innovation Systems). This work has been carried out within the Sustainable Production Initiative and the Production Area of Advance at Chalmers. The support is gratefully acknowledged.

\section{References}

1. MAX Annual Climate Report (2008), http: //www. max.se/miljo.aspx (accessed January 16, 2010)

2. Interview with Pär Larshans, $H R$ and Sustainability Manager, MAX Hamburgerrestauranger AB

3. Finnveden, G., Hauschild, M.Z., Ekvall, T., Guinée, J., Heijungs, R., Hellweg, S., Koehler, A., Pennington, D., Suh, S.: Recent Developments in Life Cycle Assessment. Journal of Environmental Management 91, 1-21 (2009)

4. Reap, J., Bras, B., Newcomb, P.J., Carmichael, C.: Improving Life Cycle Assessment by Including Spatial, Dynamic and Place-Based Modeling. In: Proceedings of DETC 2003 ASME (2003)

5. Andersson, J., Johansson, B., Berglund, J., Skoogh, A.: Framework for Ecolabeling using Discrete Event Simulation. In: Proceedings of the 2012 Spring Simulation Multiconference, Orlando, FL, USA (2012)

6. Ball, P.D., Evans, S., Levers, A., Ellison, D.: Zero carbon manufacturing facility - towards integrating material, energy, and waste process flows. Proceedings of the Institution of Mechanical Engineers, Part B: Journal of Engi-neering Manufacture 223(9), 1085-1096 (2009)

7. Maurice, B., Frischknecht, R., Coelho-Schwirtz, V., Hungerbühler, K.: Uncertainty analysis in life cycle inventory. Application to the production of electricity with French coal power plants. Journal of Cleaner Production 8, 95-108 (2000)

8. Heilala, J., Saija, V., Tonteri, H., Montonen, J., Johansson, B., Stahre, J., Lind, S.: Simulation-Based Sustainable Manufacturing System Design. In: Proceedings of the 2008 Winter Simulation Conference, pp. 1922-1930 (2008)

9. Cao, H., Chou, Y.-C.: Mobile Agent Based Integration Framework for Flexible Dynamic Job Shop Scheduling. In: Proceedings of the 2009 ASME Design for Manufacturing and the Life Cycle Conference, San Diego, California, USA, August 30- September 2 (2009)

10. Nagel, C., Meyer, P.: Caught between ecology and economy: end-of-life aspects of environmentally conscious manufacturing. Computers \& Industrial Engineering 36, 781-792 (1999)

11. Feifel, S., Walk, W., Wursthorn, S.: LCA, how are you doing today? A snapshot from the 5th German LCA workshop. International Journal of Life Cycle Assessment 15, 139-142 (2010) 
12. Skoogh, A., Johansson, B.: Time-consumption analysis of input data activities in discrete event simulation projects. In: Proceedings of the 2007 Swedish Production Symposium (2007)

13. Robertson, N., Perera, T.: Automated data collection for simulation? Simulation Practice and Theory 9, 349-364 (2002)

14. Skoogh, A., Johansson, B., Stahre, J.: Automated Input Data Management: Evaluation of a Concept for Reduced Time-Consumption in Discrete Event Simulation. Simulation: Transactions of the Society for Modeling and Simulation International 88(11), 1279-1293 (2012)

15. SISO - Simulation Interoperability Standards Organization, CMSD Product Development Group. Standard for: Core Manufacturing Simulation Data - UML Model (May 11, 2009)

16. Rabe, M., Spieckermann, S., Wenzel, S.: A New Procedure Model for Verification and Validation in Production and Logistics Simulation. In: Proceedings of the 2008 Winter Simulation Conference, pp. 1717-1726 (2008)

17. Herrmann, C., Thiede, S., Kara, S., Hesselbach, J.: Energy oriented simulation of manufacturing systems - Concept and application. CIRP Annals Manufacturing Technology 60(1), 45-48 (2011)

18. Thiede, S., Herrmann, C., Kara, S.: State of Research and an innovative Approach for simulating Energy Flows of Manufacturing Systems. In: Glocalized Solutions for Sustainability in Manufacturing CIRP Braunschweig (2011)

19. Hesselbach, J., Herrmann, C., Detzer, R., Martin, L., Thiede, S., Lüdemann, B.: Energy Efficiency through optimized coordination of production and technical building services. In: Proceeding of the 15th Conference on Life Cycle Engineering, Sydney (2008)

20. Dietmair, A., Verl, A.: A generic energy consumption model for decision making and energy efficiency optimisation in manufacturing. International Journal of Sustainable Engineering 2(2), 123 (2009)

21. Heilala, J., Vatanen, S., Tonteri, H., Montonen, J., Lind, S., Johansson, B., Stahre, J.: Simulation-based sustainable manufacturing system design. In: Mason, S.J. (Hg.) 2008 Winter Simuation Conference (2008)

22. Hornberger, M.: Total Energy Efficiency Management. Vom Energiemanagementsystem zur Simulation der Energieverbrauchswerte auf Prozessebene. In: Elektronik Ecodesign Congress, München (2009)

23. Johansson, B., Mani, M., Skoogh, A., Leong, S.: Discrete Event Simulation to generate Requirements Specification for Sustainable Manufacturing Systems Design (2009)

24. Junge, M.: Simulationsgestützte Entwicklung und Optimierung einer energieeffizienten Produktionssteuerung. Dissertation, Univ. Kassel (2007)

25. Löfgren, B.: Capturing the life cycle environmental performance of a company's manufacturing system. Göteborg. Chalmers University of Technology (2009)

26. Rahimifard, S., Seow, Y., Childs, T.: Minimising Embodied Product Energy to support energy efficient manufacturing. CIRP Annals - Manufacturing Technology 59, 25-28 (2010)

27. Solding, P., Petku, D., Mardan, N.: Using simulation for more sustainable production systems - methodologies and case studies. Journal of Sustainable Engineering 2(2), 111-122 (2009)

28. Weinert, N., Chiotellis, S., Seliger, G.: Concept for Energy-Aware Production Planning based on Energy Blocks. In: GCSM 2009: Proceedings of the 7th Global Conference on Sustainable Manufacturing, pp. 75-80 (2009)

29. Wohlgemuth, V., Page, B., Kreutzer, W.: Combining discrete event simulation and material flow analysis in a component-based approach to industrial environmental protection. Environmental Modelling \& Software 21(11), 1607-1617 (2006) 